\title{
BOUNDS FOR COMPLETELY MONOTONIC DEGREES OF REMAINDERS IN ASYMPTOTIC EXPANSIONS OF THE DIGAMMA FUNCTION
}

\author{
MANSOUR MAHMOUd AND FEng QI*
}

\begin{abstract}
Motivated by several conjectures posed in the paper "F. Qi and A.-Q. Liu, Completely monotonic degrees for a difference between the logarithmic and psi functions, J. Comput. Appl. Math. 361 (2019), 366-371; https://doi.org/10.1016/j.cam.2019.05.001”, the authors bound several completely monotonic degrees of the remainders in the asymptotic expansions of the logarithm of the gamma function and in the asymptotic expansions of the logarithm of the digamma function.
\end{abstract}

Mathematics subject classification (2020): Primary 33B15; Secondary 26A48, 41A60, 44A10.

Keywords and phrases: Completely monotonic degree, completely monotonic function, remainder, asymptotic expansion, logarithm of the gamma function, digamma function, Qi's conjecture.

\section{REFERENCES}

[1] M. Abramowitz And I. A. Stegun (Eds), Handbook of Mathematical Functions with Formulas, Graphs, and Mathematical Tables, National Bureau of Standards, Applied Mathematics Series 55, 10th printing, Dover Publications, New York and Washington, 1972.

[2] H. AlZER, On some inequalities for the gamma and psi functions, Math. Comp. 66 (1997), no. 217, 373-389; https://doi .org/10.1090/S0025-5718-97-00807-7.

[3] G. E. Andrews, R. Askey, And R. Roy, Special Functions, Encyclopedia of Mathematics and its Applications 71, Cambridge University Press, Cambridge, 1999.

[4] B. C. Berndt, Ramanujan's Notebooks, Part II, Springer-Verlag, New York, 1989; https://doi.org/10.1007/978-1-4612-4530-8.

[5] C.-P. Chen, F. QI, AND H. M. SRIVASTAVA, Some properties of functions related to the gamma and psi functions, Integral Transforms Spec. Funct. 21 (2010), no. 2, 153-164; https://doi.org/10.1080/10652460903064216.

[6] L. FlaX, Theory of the Anisotropic Heisenberg Ferromagnet, NASA Technical Note, NASA TN D-6037, National Aeronautics and Space Administration, Washington, D. C., Oct. 1970; https://ntrs.nasa.gov/archive/nasa/casi.ntrs.nasa.gov/19700033052.pdf.

[7] I. S. Gradshteyn And I. M. Ryzhik, Table of Integrals, Series, and Products, Translated from the Russian, Translation edited and with a preface by Daniel Zwillinger and Victor Moll, Eighth edition, Revised from the seventh edition, Elsevier/Academic Press, Amsterdam, 2015; https://doi.org/10.1016/B978-0-12-384933-5.00013-8.

[8] B.-N. GUO AND F. QI, A completely monotonic function involving the tri-gamma function and with degree one, Appl. Math. Comput. 218 (2012), no. 19, 9890-9897; https://doi.org/10.1016/j.amc.2012.03.075.

[9] B.-N. GUO AND F. QI, Explicit formulae for computing Euler polynomials in terms of Stirling numbers of the second kind, J. Comput. Appl. Math. 272 (2014), 251-257; https://doi.org/10.1016/j.cam.2014.05.018.

[10] B.-N. GUO AND F. QI, Some identities and an explicit formula for Bernoulli and Stirling numbers, J. Comput. Appl. Math. 255 (2014), 568-579; http://dx.doi .org/10.1016/j . cam.2013.06. 020.

[11] B.-N. GUO AND F. QI, Two new proofs of the complete monotonicity of a function involving the psi function, Bull. Korean Math. Soc. 47 (2010), no. 1, 103-111; https://doi.org/10.4134/bkms.2010.47.1.103. 
[12] B.-N. GuO, F. QI, J.-L. ZHAO, AND Q.-M. LuO, Sharp inequalities for polygamma functions, Math. Slovaca 65 (2015), no. 1, 103-120; https: //doi.org/10.1515/ms-2015-0010.

[13] S. Koumandos, Monotonicity of some functions involving the gamma and psi functions, Math. Comp. 77 (2008), no. 264, 2261-2275; https: //doi.org/10.1090/S0025-5718-08-02140-6.

[14] S. Koumandos, Remarks on some completely monotonic functions, J. Math. Anal. Appl. 324 (2006), no. 2,1458-1461; https://doi.org/10.1016/j.jmaa.2005.12.017.

[15] S. Koumandos And M. LAmprecht, Some completely monotonic functions of positive order, Math. Comp. 79 (2010), no. 271, 1697-1707; https://doi.org/10.1090/S0025-5718-09-02313-8.

[16] S. KoumAndos AND M. LAMPRECHT, Complete monotonicity and related properties of some special functions, Math. Comp. 82 (2013), no. 282, 1097-1120; https://doi.org/10.1090/S0025-5718-2012-02629-9.

[17] S. Koumandos And H. L. Pedersen, Absolutely monotonic functions related to Euler's gamma function and Barnes' double and triple gamma function, Monatsh. Math. 163 (2011), no. 1, 51-69; https://doi.org/10.1007/s00605-010-0197-9.

[18] S. Koumandos And H. L. Pedersen, Completely monotonic functions of positive order and asymptotic expansions of the logarithm of Barnes double gamma function and Euler's gamma function, J. Math. Anal. Appl. 355 (2009), no. 1, 33-40; https://doi.org/10.1016/j.jmaa.2009.01.042.

[19] W. Magnus, F. OBerhettinger, AND R. P. Soni, Formulas and Theorems for the Special Functions of Mathematical Physics, Springer, Berlin, 1966.

[20] C. Mortici, Very accurate estimates of the polygamma functions, Asympt. Anal. 68 (2010), no. 3, 125-134; https://doi.org/10.3233/ASY-2010-0983.

[21] F. W. J. Olver, D. W. Lozier, R. F. Boisvert, AND C. W. Clark (eds.), NIST Handbook of Mathematical Functions, Cambridge University Press, New York, 2010; http://dlmf .nist.gov/.

[22] F. QI, Bounds for completely monotonic degree of a remainder for an asymptotic expansion of the trigamma function, Arab J. Basic Appl. Sci. 28 (2021), no. 1, 314-318; https://doi.org/10.1080/25765299.2021.1962060.

[23] F. QI, A double inequality for the ratio of two non-zero neighbouring Bernoulli numbers, J. Comput. Appl. Math. 351 (2019), 1-5; https://doi.org/10.1016/j. cam.2018.10.049.

[24] F. QI, Completely monotonic degree of a function involving trigamma and tetragamma functions, AIMS Math. 5 (2020), no. 4, 3391-3407; https ://doi .org/10.3934/math. 2020219.

[25] F. QI, Limit formulas for ratios between derivatives of the gamma and digamma functions at their singularities, Filomat 27 (2013), no. 4, 601-604; https://doi .org/10.2298/FIL1304601Q.

[26] F. QI AND R. P. AGARWAL, On complete monotonicity for several classes of functions related to ratios of gamma functions, J. Inequal. Appl. 2019, Paper No. 36, 42 pages; https://doi.org/10.1186/s13660-019-1976-z.

[27] F. QI AND R. J. CHAPMAN, Two closed forms for the Bernoulli polynomials, J. Number Theory 159 (2016), 89-100; https://doi.org/10.1016/j.jnt.2015.07.021.

[28] F. QI AND W.-H. LI, Integral representations and properties of some functions involving the logarithmic function, Filomat 30 (2016), no. 7, 1659-1674; https://doi .org/10.2298/FIL1607659Q.

[29] F. QI AND A.-Q. LIU, Completely monotonic degrees for a difference between the logarithmic and psi functions, J. Comput. Appl. Math. 361 (2019), 366-371; https://doi.org/10.1016/j.cam.2019.05.001.

[30] F. QI, D.-W. NIU, D. LIM, AND B.-N. GUO, Closed formulas and identities for the Bell polynomials and falling factorials, Contrib. Discrete Math. 15 (2020), no. 1, 163-174; https://doi.org/10.11575/cdm.v15i1.68111.

[31] S.-L. QIU AND M. VUORINEn, Some properties of the gamma and psi functions, with applications, Math. Comp. 74 (2005), no. 250, 723-742; https://doi.org/10.1090/S0025-5718-04-01675-8.

[32] R. L. Schilling, R. Song, AND Z. VondRačEK, Bernstein Functions, 2nd ed., de Gruyter Studies in Mathematics 37, Walter de Gruyter, Berlin, Germany, 2012; https://doi.org/10.1515/9783110269338.

[33] Y. SHUANG, B.-N. GUO, AND F. QI, Logarithmic convexity and increasing property of the Bernoulli numbers and their ratios, Rev. R. Acad. Cienc. Exactas Fís. Nat. Ser. A Mat. RACSAM 115 (2021), no. 3, Paper No. 135, 12 pages; https://doi.org/10.1007/s13398-021-01071-x. 
[34] E. C. Titchmarsh, The Theory of the Riemann Zeta-Function, second edition, edited and with a preface by D. R. Heath-Brown, The Clarendon Press, Oxford University Press, New York, 1986.

[35] D. V. WIDDER, The Laplace Transform, Princeton University Press, Princeton, 1946.

[36] E. G. WINTUCKY, Formulas for nth order derivatives of hyperbolic and trigonometric functions, NASA Technical Note, NASA TN D-6403, National Aeronautics and Space Administration, Washington, D. C., July 1971; https://ntrs.nasa.gov/archive/nasa/casi.ntrs.nasa.gov/19710020296.pdf .

[37] A.-M. XU AND Z.-D. CEN, Qi's conjectures on completely monotonic degrees of remainders of asymptotic formulas of di- and tri-gamma functions, J. Inequal. Appl. 2020, Paper No. 83, 10 pages; https://doi.org/10.1186/s13660-020-02345-5.

[38] A.-M. XU AND Z.-D. CEN, Some identities involving exponential functions and Stirling numbers and applications, J. Comput. Appl. Math. 260 (2014), 201-207; https://doi.org/10.1016/j.cam.2013.09.077.

[39] Y. XU AND X. HAN, Complete monotonicity properties for the gamma function and Barnes $G$ function, Sci. Magna 5 (2009), no. 4, 47-51.

[40] Z.-H. YANG AND J.-F. TIAN, Monotonicity rules for the ratio of two Laplace transforms with applications, J. Math. Anal. Appl. 470 (2019), no. 2, 821-845; https://doi.org/10.1016/j.jmaa.2018.10.034.

[41] L. ZHU, Completely monotonic integer degrees for a class of special functions, AIMS Math. 5 (2020), no. 4, 3456-3471; https://doi.org/10.3934/math.2020224. 